\title{
Sedation in gastrointestinal endoscopy: a prospective study comparing nonanesthesiologist-administered propofol and monitored anesthesia care
}

\author{
Authors \\ Mourão ${ }^{3}$, Angelo P. Ferrari ${ }^{1,2}$ \\ Institutions \\ Universidade Federal de São Paulo - Gastroenterology, São Paulo, Brazil \\ Hospital Albert Einstein - Endoscopy, São Paulo, Brazil \\ Universidade Federal de Juiz de Fora - Physiology, Juiz de Fora, Brazil
}

Gustavo Andrade de Paulo ${ }^{1,2}$, Fernanda P.B. Martins² ${ }^{2}$ Erika P. Macedo², Manoel Ernesto P. Gonçalves ${ }^{2}$, Carlos Alberto

submitted 9. February 2014 accepted after revision 6. July 2014

\section{Bibliography Dol http://dx.doi.org/ 10.1055/s-0034-1377835 Published online: 16.1.2015 Endoscopy International Open 2015; 03: E7-E13 \\ (c) Georg Thieme Verlag KG Stuttgart · New York E-ISSN 2196-9736}

\section{Corresponding author} Gustavo Andrade de Paulo Universidade Federal de São Paulo - Gastroenterology Av. Dr. Altino Arantes 701/51 São Paulo SP 04042033 Brazil

Fax: +55-11-972833606 gustavoap@usa.net
Introduction: Adequate sedation is one of the cornerstones of good quality gastrointestinal endoscopy (GIE). Propofol sedation has increased significantly but there has been much debate over whether it can be administered by endoscopists. The aim of this prospective trial was to compare nonanesthesiologist-administered propofol (NAAP) and monitored anesthesia care (MAC). Methods: A total of 2000 outpatients undergoing GIE at Hospital Albert Einstein (São Paulo, Brazil), a tertiary-care private hospital, were divided into two matched groups: NAAP $(\mathrm{n}=1000)$ and MAC $(n=1000)$. In NAAP, propofol doses were determined by the endoscopist. A second physician stayed in the room during the entire procedure, according to local regulations. In MAC, the anesthesiologist administered propofol.

\section{Introduction}

$\nabla$

Adequate sedation and analgesia are cornerstones of good quality modern gastrointestinal endoscopy (GIE) [1]. The choice of sedative used is largely operator-dependent. A combination of benzodiazepine (mainly midazolam) and opiate (meperidine or fentanyl) is the most common approach in developed and developing countries $[2,3]$. During the last decade, all over the world, anesthesiologists and gastroenterologists (depending on local or national laws) have been increasingly using propofol (2,6 diisopropyl phenol) to replace classical sedation for GIE [4-8].

Several studies have established that propofol has many advantages over other sedative regimens. It offers a considerably quicker onset of action, less patient discomfort (less nausea and vomiting), shorter recovery time (earlier discharge), excellent patient and endoscopist satisfaction, and improved quality of endoscopy [9-12].

Nonanesthesiologist-administered

propofol

License terms

$(\circledast) \Theta \circledast$
(NAAP) has evolved as an alternative for monitored anesthesia care (MAC). It refers to direct ad-
Results: In total, 1427 patients (71.3\%) were ASA (American Society of Anesthesiologists) class I and 573 were ASA class II. In NAAP, patients received more propofol + fentanyl (61.1\% vs. $50.5 \%$; $P<0.05)$ and there were fewer cases of deep sedation (44.7\% vs. $66.1 \%$; $P<0.05)$. Hypoxemia rates were similar $(12.8 \%$ for NAAP and $11.2 \%$ for MAC; $P=0.3)$ but these reverted more rapidly in MAC (4.22 seconds vs. 7.26 seconds; $P<0.05$ ). Agitation was more frequent in MAC (14.0\% vs. 5.6\%; $P<0.05)$. No later complications were observed. Patient satisfaction was very high and similar in both groups.

Conclusion: In this setting, NAAP was as safe and effective as MAC for healthy patients undergoing GIE.

Clinical trial ref. no.: U1111-1134-4430

ministration of propofol by either a gastroenterologist or a registered nurse under the supervision of the endoscopist $[6,13,14]$.

The aim of this study was to compare NAAP with MAC for patients who were ASA (American Society of Anesthesiologists) class I or II undergoing routine endoscopic procedures.

\section{Methods \\ $\nabla$}

Patients

From October 2009 through December 2011, 2000 outpatients underwent elective upper endoscopy, colonoscopy, or both at the Endoscopy Units of Hospital Albert Einstein, São Paulo, Brazil, a tertiary care hospital. This trial was designed and monitored by the Division of Gastroenterology, Universidade Federal de São Paulo (UNIFESPEPM).

This study was submitted to the Ethics Committees of both institutions involved and was in accordance with the World Medical Association Declaration of Helsinki-Ethical Principles for 
Medical Research Involving Human Subjects. Written informed consent was obtained from all patients. For patients younger than 18 years, a parent or a legal guardian signed the consent [15].

\section{Pre-procedure preparation and assessment}

At the endoscopy room, an endoscopist and an endoscopy nurse informed the patient about the procedure (benefits, risks, limitations, and possible alternatives) whom agreed to the administration of sedation/analgesia/anesthesia.

Medical history and physical examination were performed, with emphasis on sedation-oriented issues. Major organ systems abnormalities, drug allergies, current medications, prior adverse reaction(s) to sedatives or anesthetics, recent hospital admission, and tobacco, alcohol, or illicit drugs use were evaluated. Body mass index (BMI) was calculated. Physical exam included vital signs (mean arterial blood pressure, heart rate, pulse oximetry, temperature) and examination of heart, lungs, and airway anatomy $[16,17]$. Pre-procedure assessment was documented and "time-out" was performed according to our hospital policy (accredited by the Joint Commission International). Before the administration of sedation, patients fasted for at least 3 hours after consuming clear liquids and 8 hours after meals.

Patients younger than 12 years, with BMI $>40$, or with a history of sleep apnea, prior adverse reactions to sedatives, serious drug allergies, frequent asthma crises, recent myocardial infarction, or decompensated illness (ASA class III or higher) were excluded from this study.

\section{Monitoring}

Before the procedure, an intravenous cannula was placed in the forearm for the injection of propofol and other medications. According to the recommendations of the ASA Task Force on Sedation and Analgesia by Nonanesthesiologists, supplemental oxygen $(2 \mathrm{~L} / \mathrm{min})$ was given to all patients unless specifically contraindicated [16]. Monitoring included continuous electrocardiogram, noninvasive arterial blood pressure measurement, and oximetry.

\section{Interventions}

Our hospital has two endoscopy units in different regions of São Paulo, serving similar populations. All patients who scheduled their exams at Unit 1 were enrolled in Group 1 - NAAP. All patients who scheduled their examinations at Unit 2 were enrolled in Group 2-MAC.

\section{NAAP group}

The endoscopist himself injected an initial dose of $0.5 \mathrm{mg} / \mathrm{kg}$ of propofol. It was then titrated in 10 - to $20-\mathrm{mg}$ increments to achieve appropriate sedation. Fentanyl was associated on a caseby-case basis. The endoscopist directed subsequent injections of propofol, performed by a dedicated nurse. Periods of 30 to 60 seconds were allowed between two injections of propofol to observe the drug effect before making the decision to administer the next bolus. The nurse was responsible for monitoring the patient throughout the procedure, discussing all details with the endoscopist.

To make this study possible in accordance with Brazilian regulations [18], a second physician (an anesthesiologist) stayed in the room during the entire sedation time. During the examination, he checked the depth of sedation every 2 minutes using the validated scale published by the ASA Task Force [16]. In theory, he could stop or intervene in the sedation procedure whenever he thought that the patient's safety was in jeopardy.

\section{MAC group}

The anesthesiologist performed the pre-procedure preparation and assessment of the patient. He injected an initial dose of 0.5 $\mathrm{mg} / \mathrm{kg}$ of propofol. After that, it was titrated in 10 - to $20-\mathrm{mg}$ increments to obtain appropriate sedation. Periods of 30 to $60 \mathrm{sec}-$ onds were allowed between two injections of propofol to observe the drug effect before making the decision to administer the next bolus. Other sedative drugs were used on a case-by-case basis. The anesthesiologist was also responsible for monitoring the patient throughout the procedure. He checked the depth of sedation every 2 minutes using the validated scale published by the ASA Task Force [16].

\section{Data collection and end points}

The following parameters were recorded: (1) type and dosage of drugs used; (2) level of sedation (moderate or deep); (3) minimal oxygen saturation; (4) duration of hypoxemia (oxygen saturation $\left.\left(\mathrm{SaO}_{2}\right)<85 \%\right)$ when applicable; (5) mean arterial blood pressure; (6) duration of endoscopic procedure; (7) duration of sedation/ anesthesia; (7) complications; (8) interventions aimed to treat complications (when applicable); and (9) patient satisfaction.

The following end points were defined: deepest level of sedation, hypoxia $\left(\mathrm{SaO}_{2}<85 \%\right)$, fall in mean arterial blood pressure $(>20 \%$ of index value), other complications (agitation, awakening, etc.).

\section{Training}

All endoscopists and nurses involved in this study received emergency and airway management training and were able to recognize and manage ventilatory complications associated with sedation, as recommended by the American Society for Gastrointestinal Endoscopy (ASGE) position statement $[13,17,19]$. This training was conducted by the Anesthesiology Department and was accredited by our Hospital Board. Some of the endoscopists participating in this study were also trained in advanced cardiac life support. Emergency equipment was available in every endoscopy room $[16,20]$.

\section{Follow-up}

Patients were followed-up until discharge from the endoscopy unit. Patient's memories and satisfaction were recorded as soon as their level of consciousness was completely restored. They had to fill in a structured questionnaire measuring satisfaction with aspects related to the endoscopic procedure and sedation.

\section{Statistical analysis}

A sample size calculation was performed using the Statcalc function of Epilnfo Version 6 statistical software. We considered a complication rate due to sedation of $0.1 \%$ in patients undergoing endoscopic procedures. Assuming a confidence interval of $95 \%$, a power of $80 \%$, a 1:1 ratio between MAC and NAAP, and an exposure (complication rate) of $0.15 \%$ in NAAP, we would need 82341 patients in each arm (total 164682 patients). Due to time limitations, we reduced the number of patients to 2000 making this study possible.

For continuous parameters, results were expressed as mean (SD). Categorical data were expressed using absolute frequencies and percentages. Each continuous parameter was analyzed with the two-sample Student's unpaired $t$ test. Categorical data were examined with Fisher's Exact Test. The level of statistical signifi- 


\begin{tabular}{|c|c|c|c|}
\hline Characteristics & $\begin{array}{l}\text { NAAP group } \\
(n=1000)\end{array}$ & $\begin{array}{l}\text { MAC group } \\
(n=1000)\end{array}$ & $P$-value \\
\hline Gender & & & 0.07 \\
\hline Male, n (\%) & $535(53.5)$ & $493(49.3)$ & \\
\hline Female, $\mathrm{n}(\%)$ & $465(46.5)$ & $507(50.7)$ & \\
\hline Age, mean (SD), years & $47.55(13.9)$ & $47.8(14.54)$ & 0.7 \\
\hline $\mathrm{BMI}(\mathrm{SD}), \mathrm{kg} / \mathrm{m}^{2}$ & $23.97(4.09)$ & $23.9(2.72)$ & 0.57 \\
\hline ASA Class & & & 1 \\
\hline $\mathrm{I}, \mathrm{n}(\%)$ & $714(71.4)$ & $713(71.3)$ & \\
\hline II, n (\%) & $286(28.6)$ & $287(28.7)$ & \\
\hline $\mathrm{SaO}_{2}$ (SD) before the procedure, \% & $96.93(1.21)$ & $96.87(1.28)$ & 0.28 \\
\hline $\begin{array}{l}\text { Mean blood pressure (SD) before the } \\
\text { procedure, } \mathrm{mmHq}\end{array}$ & $92.68(13.67)$ & $91.85(10.39)$ & 0.11 \\
\hline
\end{tabular}

Table 1 Comparison of clinical features.

\begin{tabular}{|c|c|c|c|}
\hline Characteristics & $\begin{array}{l}\text { NAAP group } \\
(n=1000)\end{array}$ & $\begin{array}{l}\text { MAC group } \\
(n=1000)\end{array}$ & $P$-value \\
\hline Drugs used & & & $<0.05$ \\
\hline Propofol, n (\%) & 389 (38.9) & $495(49.5)$ & \\
\hline Propofol + Fentanyl, n (\%) & $611(61.1)$ & $505(50.5)$ & \\
\hline \multicolumn{4}{|l|}{ Mean dose of drugs } \\
\hline Propofol (SD), mg & $188.4(78.87)$ & $257.02(78.44)$ & $<0.05$ \\
\hline Fentanyl (SD), $\mu g^{1}$ & $54.75(14.65)$ & $50.4(4.45)$ & $<0.05$ \\
\hline Deepest level of sedation & & & $<0.05$ \\
\hline Moderate, n (\%) & $553(55.3)$ & $339(33.9)$ & \\
\hline Deep, n (\%) & $447(44.7)$ & $661(66.1)$ & \\
\hline
\end{tabular}

Table 2 Comparison of sedative regimens.

${ }^{1}$ Considering only the patients who received it.

\begin{tabular}{|c|c|c|c|}
\hline Characteristics & $\begin{array}{l}\text { NAAP group } \\
(n=1000)\end{array}$ & $\begin{array}{l}\text { MAC group } \\
(n=1000)\end{array}$ & $P$-value \\
\hline Procedure length (SD), min & $11.43(8.66)$ & $13.9(14.22)$ & 0.61 \\
\hline Sedation length (SD), min & $16.51(9.25)$ & $17.38(14.79)$ & $<0.05$ \\
\hline Hypoxia $\left(\mathrm{SaO}_{2}<85 \%\right), \mathrm{n}(\%)$ & $128(12.8)$ & $112(11.2)$ & 0.3 \\
\hline Lowest $\mathrm{SaO}_{2}$, mean (SD), \% & $\begin{array}{l}91.19(6.9) \\
\text { Range }(30-100)\end{array}$ & $\begin{array}{l}90.03(7.37) \\
\text { Range }(40-100)\end{array}$ & $<0.05$ \\
\hline Time of hypoxia, mean (SD), s & $\begin{array}{l}7.26(17.69) \\
\text { Range }(0-150)\end{array}$ & $\begin{array}{l}4.22(13.07) \\
\text { Range }(0-120)\end{array}$ & $<0.05$ \\
\hline Bag-mask ventilation, n (\%) & $3(0.3)$ & $6(0.6)$ & 0.51 \\
\hline Fall in mean BP $>20 \%, n(\%)^{1}$ & $261(26.1)$ & $178(17.8)$ & $<0.05$ \\
\hline Awakening, $\mathrm{n}(\%)$ & 119 (11.9) & $105(10.5)$ & 0.36 \\
\hline Agitation, n (\%) & $56(5.6)$ & $140(14.0)$ & $<0.05$ \\
\hline
\end{tabular}

Table 3 Comparison of procedure and sedation length, vital parameters and complications during sedation. cance was taken as $P<0.05$ [21]. All statistical analyses were performed with SPSS for Windows (SPSS version 13.0, SPSS Inc.) statistical software or EpiInfo 6 (CDC and WHO).

\section{Results}

$\nabla$

Of the 2000 patients included in this study, 1000 received NAAP and 1000 were enrolled in the MAC group.There were 1028 male patients (51.4\%) and mean age was 47.7 (range: 12 to 90 ). Overall, 1138 (56.9\%) patients underwent upper endoscopy, 552 (27.6\%) colonoscopy, and 310 (15.5\%) underwent both examinations during the same sedation.

Mean BMI was 23.94 (range: 14.9-37.5). There were 1427 patients (71.3\%) in ASA class I.

Clinical features and initial monitoring parameters of both groups are compared in 0 Table 1. In the NAAP group, 563 (56.3\%) underwent upper endoscopy, 278 (27.8\%) colonoscopy and $159(15.9 \%)$ were submitted to both procedures. In the MAC group, 575 patients (57.5\%) underwent upper endoscopy, $274(27.4 \%)$ colonoscopy and $151(15.1 \%)$ were submitted to both examinations $(P=0.83)$. $\bigcirc$ Table 2 shows the different regimens and doses of sedative agents used and the deepest level of sedation attained.

Procedure and sedation length, hypoxia and hypotension episodes, mean lowest $\mathrm{SaO}_{2}$ and blood pressure, and agitation and awakening rates are shown in $\bullet$ Table 3 .

Other complications observed during this study included: transient arrhythmia (1), laryngeal spasm (4), and nasal bleeding (1). In $9(0.45 \%)$ patients with hypoxemia (6 in MAC group), the exam had to be temporarily interrupted for bag-mask ventilation $(P=$ 0.51 ).

- Table 4, $\odot$ Table 5, and $\odot$ Table 6 show the results of different comparisons according to the type of examination performed. In the NAAP group, 36 patients $(3.6 \%)$ had memories of the endoscopic procedure. Only one patient in the MAC group re- 


\begin{tabular}{|c|c|c|c|}
\hline Characteristics & $\begin{array}{l}\text { NAAP group } \\
(n=563)\end{array}$ & $\begin{array}{l}\text { MAC group } \\
(n=575)\end{array}$ & $P$-value \\
\hline BMI (SD), $\mathrm{kg} / \mathrm{m}^{2}$ & $24.18(4.37)$ & $23.62(2.76)$ & 0.11 \\
\hline ASA class & & & 0.67 \\
\hline I, n (\%) & $402(71.4)$ & $418(72.7)$ & \\
\hline II, n (\%) & $161(28.6)$ & $157(27.3)$ & \\
\hline Deepest level of sedation & & & $<0.05$ \\
\hline Moderate, n (\%) & $300(53.29)$ & $87(15.13)$ & \\
\hline Deep, n (\%) & $263(46.71)$ & $488(84.87)$ & \\
\hline Procedure length (SD), min & $6.24(4.22)$ & $5.96(2.04)$ & $<0.05$ \\
\hline Sedation length (SD), min & $11.22(4.45)$ & $9.05(2.58)$ & $<0.05$ \\
\hline Hypoxia $\left(\mathrm{SaO}_{2}<85 \%\right), \mathrm{n}(\%)$ & $67(11.9)$ & $49(8.52)$ & 0.07 \\
\hline Bag-mask ventilation, n (\%) & 0 & $3(0.52)$ & 0.24 \\
\hline Fall in mean $\mathrm{BP}>20 \%, \mathrm{n}(\%)^{1}$ & $107(19.0)$ & $89(15.48)$ & 0.13 \\
\hline Awakening, $\mathrm{n}(\%)$ & $28(4.97)$ & $49(8.52)$ & $<0.05$ \\
\hline Agitation, n (\%) & $21(3.73)$ & $69(12)$ & $<0.05$ \\
\hline
\end{tabular}

Table 4 Comparison of procedure and sedation length, vital parameters and complications during sedation for patients undergoing Upper Endoscopy.

\begin{tabular}{|c|c|c|c|}
\hline Characteristics & $\begin{array}{l}\text { NAAP group } \\
(\mathrm{n}=278)\end{array}$ & $\begin{array}{l}\text { MAC group } \\
(n=274)\end{array}$ & $P$-value \\
\hline BMI (SD), kg/m² & $23.58(3.64)$ & $24.28(2.56)$ & $<0.05$ \\
\hline ASA class & & & 0.16 \\
\hline I, n (\%) & $196(70.5)$ & $177(64.6)$ & \\
\hline II, n (\%) & $82(29.5)$ & $97(35.4)$ & \\
\hline Deepest level of sedation & & & 0.32 \\
\hline Moderate, n (\%) & $160(57.55)$ & $104(37.96)$ & \\
\hline Deep, n (\%) & $118(42.45)$ & $170(62.05)$ & \\
\hline Procedure length (SD), min & $16.66(8.21)$ & $21.29(14.35)$ & $<0.05$ \\
\hline Sedation length (SD), min & $21.89(9.21)$ & $25.37(14.76)$ & 0.08 \\
\hline Hypoxia $\left(\mathrm{SaO}_{2}<85 \%\right), \mathrm{n}(\%)$ & $31(11.15)$ & $44(16.06)$ & 0.12 \\
\hline Bag-mask ventilation, n (\%) & 0 & $2(0.73)$ & 0.25 \\
\hline Fall in mean $\mathrm{BP}>20 \%, \mathrm{n}(\%)^{1}$ & $101(36.33)$ & $58(21.17)$ & $<0.05$ \\
\hline Awakening, n (\%) & $65(23.38)$ & $38(13.87)$ & $<0.05$ \\
\hline Agitation, $\mathrm{n}(\%)$ & $22(7.91)$ & $48(17.52)$ & $<0.05$ \\
\hline
\end{tabular}

Table 5 Comparison of procedure and sedation length, vital parameters and complications during sedation for patients undergoing Colonoscopy.

${ }^{1}$ When compared with the initial value.

\begin{tabular}{|c|c|c|c|}
\hline Characteristics & $\begin{array}{l}\text { NAAP group } \\
(n=159)\end{array}$ & $\begin{array}{l}\text { MAC group } \\
(n=151)\end{array}$ & $P$-value \\
\hline $\mathrm{BMI}(\mathrm{SD}), \mathrm{kg} / \mathrm{m}^{2}$ & $23.91(3.76)$ & $24.3(2.72)$ & 0.2 \\
\hline ASA class & & & 0.35 \\
\hline I, n (\%) & $116(72.96)$ & $118(78.15)$ & \\
\hline II, n (\%) & $43(27.04)$ & $33(21.85)$ & \\
\hline Deepest level of sedation & & & 0.53 \\
\hline Moderate, n (\%) & $93(58.49)$ & $82(54.3)$ & \\
\hline Deep, n (\%) & $66(41.51)$ & $69(45.7)$ & \\
\hline Procedure length (SD), min & $20.67(7.94)$ & $30.74(18.15)$ & $<0.05$ \\
\hline Sedation length (SD), min & $25.82(9.17)$ & $34.6(18.82)$ & $<0.05$ \\
\hline Hypoxia $\left(\mathrm{SaO}_{2}<85 \%\right), \mathrm{n}(\%)$ & $30(18.87)$ & $19(12.58)$ & 0.17 \\
\hline Bag-mask ventilation, n (\%) & $3(1.89)$ & $1(0.66)$ & 0.62 \\
\hline Fall in mean $B P>20 \%, n(\%)^{1}$ & $53(33.33)$ & $31(20.53)$ & $<0.05$ \\
\hline Awakening, $\mathrm{n}(\%)$ & $26(16.35)$ & $18(11.92)$ & 0.34 \\
\hline Agitation, n (\%) & $13(8.18)$ & $23(15.23)$ & 0.08 \\
\hline
\end{tabular}

Table 6 Comparison of procedure and sedation length, vital parameters and complications during sedation for patients undergoing Upper Endoscopy and Colonoscopy. membered the exam $(P<0.05)$. When asked about the quality of sedation, 392 patients (39.2\%) in NAAP found it similar to previous examinations. In total, 371 patients $(37.1 \%)$ found it better, and $13(1.3 \%)$ judged it worst. On the other hand, $224 \mathrm{pa}-$ tients $(22.4 \%)$ had their exams for the first time and could not compare it with a previous exam. Only four patients $(0.4 \%)$ said they would not repeat the procedure in the same manner. In the MAC group, 516 patients (51.6\%) found it similar, and 76 (7.6\%) judged it better, whereas 408 (40.8\%) could not compare it (first examination). All patients but three declared they would repeat the procedure. 


\section{Discussion}

\section{$\nabla$}

According to the Standards of Practice Committee of the American Society for Gastrointestinal Endoscopy (ASGE), "sedation may be defined as a drug-induced depression in the level of consciousness" [17]. Sedation and analgesia for GIE aim to relieve the patient's anxiety, fear and pain, minimize discomfort, improve the outcome of the examination, and diminish the patient's recollection of the event $[16,17,22-26]$. Although their use improves tolerance and acceptance of the examination, they increase the cost and are responsible for about $50 \%$ of all GIE complications $[20,22,27,28]$.

Sedation and analgesia represent a continuum ranging from minimal (anxiolysis) or moderate to deep sedation and general anesthesia $[16,17,24,25,29]$. Moderate sedation is recommended as it provides adequate anxiolysis, pain control, and amnesia, being safer than deep sedation $[25,30]$. There is a clear difference in the need for sedation related to cultural factors in different countries. In Brazil, patients are very resistant to procedures without any type of sedation.

The use of propofol during GIE has increased dramatically in the last decade, mainly due to its favorable pharmacokinetic profile [6,31-33]. Its onset of action is almost instantaneous and its half-life is of only 2 to 4 minutes, allowing a rapid recovery. Its main disadvantages include pain at the injection site (up to $30 \%$ ), potential for deeper levels of sedation, and lack of antagonist [17, 34].

In a nationwide survey in the United States, $25.7 \%$ of responders preferred propofol [35]. In a similar query in Switzerland, $43 \%$ of gastroenterologists reported its use [36]. In an international observational study performed in 11 countries (21 centers), propofol was administered for deep sedation during $29.9 \%$ of colonoscopies [37].

At least three systematic reviews have assessed the safety and performance of propofol versus traditional sedative agents used in GIE. In the meta-analysis (12 studies, 1161 patients) performed by Qadeer et al., it was observed that "propofol sedation during colonoscopy appears to have lower odds of cardiopulmonary complications compared with traditional agents, but for other procedures, the risk of complications is similar" [38]. In a Cochrane Systematic Review on propofol use during colonoscopy (20 studies), Singh et al. concluded that "for generally healthy individuals, it can lead to faster recovery and discharge times, increased patient satisfaction without an increase in side-effects" [39]. Recently, McQuaid and Laine analyzed 36 studies (3918 patients) and concluded that there were no significant differences in most important clinical outcomes for upper endoscopy but there was a higher proportion of patient satisfaction for colonoscopy with propofol sedation when compared with midazolam. Recovery times for both endoscopy and colonoscopy were shorter with propofol [30].

Given the evolving healthcare overhaul and the general push towards cost containment, the use of anesthesiologist-administered sedation for healthy, low risk patients undergoing routine GIE, with no proven benefit with respect to patient safety or procedural efficacy, seems unlikely and not sustainable $[8,13,40]$.

Despite strong evidence that NAAP is safe without the involvement of an anesthesia specialist, its use is controversial and has moved forward only slowly, because anesthesiologists claim that it is unsafe [6]. The obstacles to NAAP have been political, and these political factors are largely motivated by financial issues [14]. Because there is virtually no evidence to support the posi- tion that nonanesthesiologists cannot administer propofol, the anesthesia community often quote the warning contained in the package insert that propofol should be given only by persons trained in the administration of general anesthesia $[6,14,31]$. However, the package insert was written before evidence accumulated that NAAP is safe [6]. Thus far, the safety record of NAAP is superior to reports of gastrointestinal-directed opioid and benzodiazepine sedation for endoscopy and is equal to the reported record of anesthesiologists administering general anesthesia $[14,20,28,41]$.

Several significant studies, including a recently published worldwide safety survey of 646080 procedures with NAAP, have provided additional evidence supporting its safety $[6,8]$. Hence, the four major gastroenterology societies in the United States issued a consensus statement supporting the expansion of NAAP [13]. This was also endorsed by $97 \%$ of the experts gathered in a panel in Athens sponsored by the World Organization of Digestive Endoscopy and the European Society of Gastrointestinal Endoscopy [42]. However, the practice of NAAP continues to generate controversy and debate.

In 2010, the European Society of Gastrointestinal Endoscopy (ESGE), the European Society of Gastroenterology and Endoscopy Nurses and Associates (ESGENA) and the European Society of Anesthesiology (ESA) issued a guideline on the use of propofol for gastrointestinal endoscopy by nonanesthesiologists [20]. This guideline was written by a committee working together in an attempt to improve the quality and safety of care for patients undergoing gastrointestinal interventions and was completely in line with the recommendations made by the European Board of Anesthesiology [43]. However, in 2012, the ESA retracted its endorsement of the guideline [44]. This retraction might have been for political rather than scientific reasons [45].

Even though there has been a huge debate whether NAAP is better than or at least as good as MAC, to our knowledge, this is the first prospective case-control trial that compared both regimens.

This study was only possible because our hospital is one of the very few in Brazil that uses MAC for all endoscopic procedures (apart from those with a formal contraindication to propofol). Thus, an anesthesiology team with extensive experience in endoscopic procedures is on duty at the endoscopy unit 24 hours a day. Although it is not cost-effective, as demonstrated in a sensitive analysis performed by Vargo et al. [46], it is in accordance with local laws. In Brazil, deep sedation can only be performed by qualified physicians in adequate facilities. Patient care cannot be left in the hands of the physician performing a procedure that requires sedation. A designated physician other than the practitioner performing the procedure should be present to monitor the patient throughout the procedure performed with sedation/ analgesia [18]. This is also supported by the Practice Guidelines for Sedation and Analgesia by Nonanesthesiologists issued by the ASA [16]. What is more, our hospital is one of the largest private hospitals in São Paulo (over 10 million people) and has two endoscopy units in different regions of the city, serving similar populations. As the authors work in both units, we could use each unit for a different group in the study.

In the NAAP group in this study, an anesthesiologist stayed in the room during the entire procedure. He was in charge of collecting data. We do understand that the presence of a second physician (anesthesiologist) inside the endoscopy room might alter the way the endoscopist conducts sedation, reminding him to be more careful with regard to doses used and airway safety con- 
cerns. However, this was the only possible way to conduct this kind of study in accordance with local medical regulations. Although the second physician was allowed to intervene in the sedation procedure (in theory), this did not happen during the entire study. All complications (hypoxia, fall in blood pressure, laryngeal spasm, etc.) were handled exclusively by the endoscopist in charge with the help of the dedicated nurse, with no later complications. What is more, as the anesthesiologists knew that their sedations/anesthesias were being recorded (MAC group), the presence of the endoscopist conducting the study was also a reminder for them to be more cautious.

A sample size calculation was performed before starting this protocol. However, owing to the reduced complication rate of endoscopic procedures $(0.05 \%$ to $0.54 \%$ ) [1], the number of patients needed to compare the two groups was practically impossible to achieve in a single center. For this reason, we limited our study to 2000 patients.

In our series, both groups were very similar according to gender, age, ASA class, BMI and initial $\mathrm{SaO}_{2}$. Both groups were in the normal range of BMI (up to $25 \mathrm{~kg} / \mathrm{m}^{2}$ ) and the slightly higher index in NAAP did not interfere with blood pressure or any other clinical parameter.

In NAAP, there was a higher use of fentanyl plus propofol $(61.1 \%$ vs. $50.5 \%$; $P<0.05$ ). The association of fentanyl is also the probable explanation for the reduced mean dose of propofol in the NAAP group (188.4 mg vs. $257.02 \mathrm{mg} ; P<0.05$ ). This combination has synergic effects and may have advantages over the use of propofol as a single agent $[13,20,23,28,47-49]$.

The reduced mean dose of propofol in the NAAP group is also a plausible explanation for the higher incidence of moderate sedation in this group. As anesthesiologists administered higher doses of propofol, they had a significant increase in the frequency of deep sedation (66.1\% vs. $44.7 \%$; $P<0.05$ ). This is in accordance with the work of Poincloux et al. [49]. It is important to mention that sedation was always targeted to a moderate level. However, individuals differ in their response to sedation and moments of deep sedation and even general anesthesia might have occurred during the procedure (without any clinical consequence).

We defined hypoxemia when peripheral saturation was below $85 \%$, according to Rex et al. [50]. This level was adopted in other studies [37,51]. Although we observed 240 (12.0\%) episodes of hypoxemia, the mean value of the lowest $\mathrm{SaO}_{2}$ levels was above $90 \%$ in both groups.

In our study, $12.8 \%$ of patients in the NAAP group experienced hypoxemia. This was rapidly reverted (mean time: 7.26 seconds) thanks to an increase in supplemental oxygen, back tilt of the head, chin lift, and jaw thrust. All of these maneuvers were initiated as soon as the $\mathrm{O}_{2}$ saturation level started to decline. A decline greater than $20 \mathrm{mmHg}$ in mean arterial blood pressure was observed in $26.1 \%$ of patients. In all cases, this responded to fluid administration. No later complications due to hypoxemia or hypotension were observed. These results are similar to those observed by Cohen et al. in 819 patients ( $9 \%$ of hypoxemia and 27 $\%$ of hypotension) [34]. In the systematic review performed by McQuaid and Laine, the pooled incidence of hypoxemia was $11 \%$ (5\% for hypotension) [30]. In the German Guideline for Sedation for Gastrointestinal Endoscopy, the incidence of hypoxemia $\left(\mathrm{SaO}_{2}<90 \%\right)$ with the use of propofol ranged from $8.2 \%$ to $57 \%$ [28]. In our MAC group, $11.2 \%$ of patients experienced hypoxemia, and this reverted after a mean of 4.22 seconds. It is important to mention that, although statistically significant, this differ- ence had no later consequences as all patients were discharged without any sequelae.

Only nine patients $(0.45 \%)$ in the entire cohort presented hypoxemia that required bag-mask ventilation. This is in accordance with other published results (range: 0 to $1 \%$ ) [14]. The need for mask ventilation according to the German Guideline is $0.4 \%$ [28]. None of our patients needed endotracheal intubation.

The higher prevalence of mask ventilation in the MAC group ( $0.6 \%$ vs. $0.3 ; P=0.51)$ might be an explanation for the longer duration of procedures, as they had to be interrupted and restarted after normalization of oxygen saturation. No patient had any later complications due to hypoxemia.

Awakening during sedation was observed with similar frequencies in both groups. However, agitation was higher in the MAC group ( $14.0 \%$ vs. $5.6 \%$; $P<0.05$ ). This difference might also be explained by the higher frequency of fentanyl use in the NAAP group. What is more, as the endoscopist knows how the procedures are running, he is more capable of controlling the doses of propofol required and the moments of injection (passage of the upper esophageal sphincter, passage through the sigmoid, etc.). In the NAAP group, $3.6 \%$ of patients had memories of the endoscopic procedure. Only one patient in the MAC group remembered the exam. These results are significantly lower than those observed in the systematic review by McQuaid and Laine where more than one-third of the patients reported memory from the procedure when propofol was used [30]. One possible explanation for this difference is the higher doses of sedatives used in our study.

In the same review, a high level of patient satisfaction (88\%) was observed, and $87 \%$ of them were willing to repeat the same procedure with propofol sedation [30]. In our series, only $0.4 \%$ of patients in the NAAP group reported they would not repeat the sedation scheme. Again, the deeper level of sedation might be associated with a greater level of satisfaction by patients undergoing endoscopic examinations.

The role of anesthesiologists in the field of gastrointestinal endoscopy has changed significantly in the past decades but it must evolve further. Their participation in the care of the more fragile patients (ASA III or higher, elderly), people with difficult airways or a history of inadequate response to sedation and those undergoing the most complex procedures, is unquestionable. We do agree that it is of the utmost importance that they collaborate in the formulation of sedation and/or analgesia guidelines for nonanesthetic medical personnel with adequate minimum guarantees for safety and quality of care [52]. Hence, they can be directly involved in the appropriate training of endoscopists and nurses for propofol administration to low risk patients [14].

In conclusion, for patients of ASA class I and II undergoing endoscopic procedures, NAAP can be as safe and effective as MAC. We believe that propofol use by nonanesthesiologists will evolve in the future owing to its pharmacokinetic and safety profiles and the increased workload of endoscopy units. The development of well-defined guidelines through close collaboration between gastroenterologists and anesthesiologists (endorsed by medical societies and national laws) will improve the quality and safety of sedation administration to patients undergoing endoscopic procedures [52].

\section{Competing interests: None}




\section{References}

1 Waring JP, Baron TH, Hirota WK et al. Guidelines for conscious sedation and monitoring during gastrointestinal endoscopy. Gastrointest Endosc 2003; 58: $317-322$

2 Benson AA, Cohen LB, Waye JD et al. Endoscopic sedation in developing and developed countries. Gut Liver 2008; 2: 105-112

3 O'Connor JP, O'Morain CA, Vargo JJ. Computer-assisted propofol administration. Digestion 2010; 82: 124-126

4 Aisenberg J, Brill JV, Ladabaum $U$ et al. Sedation for gastrointestinal endoscopy: new practices, new economics. Am J Gastroenterol 2005; 100: $996-1000$

5 Faulx AL, Vela S, Das A et al. The changing landscape of practice patterns regarding unsedated endoscopy and propofol use: a national Web survey. Gastrointest Endosc 2005; 62: 9-15

6 Rex DK, Deenadayalu VP, Eid E et al. Endoscopist-directed administration of propofol: a worldwide safety experience. Gastroenterology 2009; 137: 1229 - 1237 ; quiz 518-519

7 Dinis-Ribeiro M, Vargo JJ. Sedation by non-anesthesiologists: are opioids and benzodiazepines outdated? Digestion 2010; 82: 100 - 101

8 Berzin TM. Endoscopic sedation training in gastroenterology fellowship. Gastrointest Endosc 2010; 71: 597-599

9 Kulling $D$, Orlandi $M$, Inauen $W$. Propofol sedation during endoscopic procedures: how much staff and monitoring are necessary? Gastrointest Endosc 2007; 66: $443-449$

10 Byrne MF, Chiba N, Singh $H$ et al. Propofol use for sedation during endoscopy in adults: a Canadian Association of Gastroenterology position statement. Can J Gastroenterol 2008; 22: 457-459

11 Tohda G, Higashi $S$, Wakahara $S$ et al. Propofol sedation during endoscopic procedures: safe and effective administration by registered nurses supervised by endoscopists. Endoscopy 2006; 38: 360-367

12 Heuss LT, Peter S. Propofol use by gastroenterologists - the European experience. Gastrointest Endosc Clin N Am 2008; 18: 727 - 738, ix

13 Vargo JJ, Cohen LB, Rex DK et al. Position statement: nonanesthesiologist administration of propofol for GI endoscopy. Gastrointest Endosc 2009; 70: 1053 - 1059

14 Rex DK, Deenadayalu V, Eid E. Gastroenterologist-directed propofol: an update. Gastrointest Endosc Clin N Am 2008; 18: 717-725, ix

15 Zuckerman MJ, Shen B, Harrison ME et al. Informed consent for GI endoscopy. Gastrointest Endosc 2007; 66: 213-218

16 American Society of Anesthesiologists. Practice guidelines for sedation and analgesia by non-anesthesiologists. Anesthesiology 2002; 96 : $1004-1017$

17 Lichtenstein DR, Jagannath S, Baron TH et al. Sedation and anesthesia in GI endoscopy. Gastrointest Endosc 2008; 68: 815-826

18 Conselho Federal De Medicina. Resolução CFM 1.670/03 (Publicada no D.O.U. 14 July 2003, section I, p. 78). Available from: http://www.portalmedico.org.br/resolucoes/CFM/2003/1670_2003.htm

19 Vargo JJ, Delegge $M H$, Feld $A D$ et al. Multisociety sedation curriculum for gastrointestinal endoscopy. Gastrointest Endosc 2012; 76: e1 - e25

20 Dumonceau JM, Riphaus A, Aparicio JR et al. European Society of Gastrointestinal Endoscopy, European Society of Gastroenterology and Endoscopy Nurses and Associates, and the European Society of Anaesthesiology Guideline: Non-anesthesiologist administration of propofol for GI endoscopy. Endoscopy 2010; 42: 960-974

21 Armitage P, Berry G. Statistical methods in medical research. 3rd: edn. Oxford: Blackwell Science; 1994

22 Ladas $S D$. Sedation for gastrointestinal endoscopy. Editorial. Digestion 2010; 82: 73

23 Kerker A, Hardt C, Schlief HE et al. Combined sedation with midazolam/ propofol for gastrointestinal endoscopy in elderly patients. BMC Gastroenterol 2010; 10: 11

24 Faigel DO, Baron TH, Goldstein JL et al. Guidelines for the use of deep sedation and anesthesia for GI endoscopy. Gastrointest Endosc 2002; 56 : $613-617$

25 Morse J, Bamias G. Ability to reverse deeper levels of unintended sedation. Digestion 2010; 82: $94-96$

26 Paspatis GA, Tribonias G, Paraskeva $K$. Level of intended sedation. Digestion 2010; 82: 84-86

27 Ladas SD, Satake Y, Mostafa I et al. Sedation practices for gastrointestinal endoscopy in Europe, North America, Asia, Africa and Australia. Digestion 2010; 82 : $74-76$
28 Riphaus A, Wehrmann T. S3 Guideline: Sedation for gastrointestinal endoscopy 2008. Endoscopy 2009; 41: 787-815

29 Wehrmann T. Extended monitoring of the sedated patient: bispectral index, Narcotrend and automated responsiveness monitor. Digestion 2010; 82: 90 - 93

30 McQuaid KR, Laine L. A systematic review and meta-analysis of randomized, controlled trials of moderate sedation for routine endoscopic procedures. Gastrointest Endosc 2008; 67: 910-923

31 Wehrmann $T$, Triantafyllou $K$. Propofol sedation in gastrointestinal endoscopy: a gastroenterologist's perspective. Digestion 2010; 82: $106-109$

32 Riphaus A, Wehrmann T. Sedation and preparation. Endoscopy 2011; 43: $63-66$

33 Heuss LT, Froehlich F, Beglinger C. Nonanesthesiologist-administered propofol sedation: from the exception to standard practice. Sedation and monitoring trends over 20 years. Endoscopy 2012; 44: 504-511

34 Cohen LB, Dubovsky AN, Aisenberg J et al. Propofol for endoscopic sedation: A protocol for safe and effective administration by the gastroenterologist. Gastrointest Endosc 2003; 58: 725-732

35 Cohen LB, Wecsler JS, Gaetano JN et al. Endoscopic sedation in the United States: results from a nationwide survey. Am J Gastroenterol 2006; 101: $967-974$

36 Heuss LT, Froehlich F, Beglinger C. Changing patterns of sedation and monitoring practice during endoscopy: results of a nationwide survey in Switzerland. Endoscopy 2005; 37: 161 - 166

37 Froehlich F, Harris JK, Wietlisbach Vet al. Current sedation and monitoring practice for colonoscopy: an International Observational Study (EPAGE). Endoscopy 2006; 38: 461 - 469

38 Qadeer MA, Vargo JJ, Khandwala $F$ et al. Propofol versus traditional sedative agents for gastrointestinal endoscopy: a meta-analysis. Clin Gastroenterol Hepatol 2005; 3: 1049 - 1056

39 Singh $H$, Poluha $W$, Cheung $M$ et al. Propofol for sedation during colonoscopy. Cochrane Database Syst Rev 2008: CD006268

40 Dumonceau JM. Nonanesthesiologist administration of propofol: it's all about money. Endoscopy 2012; 44: 453-455

41 Lee CK, Lee SH, Chung IK et al. Balanced propofol sedation for therapeutic GI endoscopic procedures: a prospective, randomized study. Gastrointest Endosc 2011; 73: 206 - 214

42 Cohen LB, Ladas SD, Vargo JJ et al. Sedation in digestive endoscopy: the Athens international position statement. Aliment Pharmacol Ther 2010; 32: $425-442$

43 Knape JT, Adriaensen $H$, van Aken $H$ et al. Guidelines for sedation and/or analgesia by non-anaesthesiology doctors. Eur J Anaesthesiol 2007; 24: $563-567$

44 Pelosi P. Retraction of endorsement: European Society of Gastrointestinal Endoscopy, European Society of Gastroenterology and Endoscopy Nurses and Associates, and the European Society of Anaesthesiology Guideline: Non-anesthesiologist administration of propofol for GI endoscopy. Endoscopy 2012; 44: 302

45 Dumonceau JM, Riphaus A. Reply to Pelosi. Endoscopy 2012; 44: 300

46 Vargo JJ, Zuccaro GJr, Dumot JA et al. Gastroenterologist-administered propofol versus meperidine and midazolam for advanced upper endoscopy: a prospective, randomized trial. Gastroenterology 2002; $123: 8-16$

47 Vargo J. Risks of sedation and analgesia. Tech Gastrointest Endosc 2007; 9: 218-224

48 Wehrmann T, Riphaus A. Sedation with propofol for interventional endoscopic procedures: a risk factor analysis. Scand J Gastroenterol 2008; 43: $368-374$

49 Poincloux L, Laquiere A, Bazin JE et al. A randomized controlled trial of endoscopist vs. anaesthetist-administered sedation for colonoscopy. Dig Liver Dis 2011; 43: $553-558$

50 Rex DK, Overley C, Kinser K et al. Safety of propofol administered by registered nurses with gastroenterologist supervision in 2000 endoscopic cases. Am J Gastroenterol 2002; 97: 1159-1163

51 Marcondes G, Soeiro FS, Ferreira Ede A et al. Transportation of patients to the post-anesthetic recovery room without supplemental oxygen: repercussions on oxygen saturation and risk factors associated with hypoxemia. Rev Bras Anestesiol 2006; 56: 352-361

52 Van der Linden P. Sedation in gastrointestinal endoscopy: an anesthesiologist's perspective. Digestion 2010; 82: $102-105$ 